\title{
1 Response patterns and mechanisms of plants to water stress
}

2 Yuan Sun ${ }^{\mathrm{a}}$, Cuiting Wang ${ }^{\mathrm{a}}$, Han Y.H. Chen ${ }^{\mathrm{b}}$, Honghua Ruan ${ }^{\mathrm{a} *}$

$3{ }^{a}$ College of Biology and the Environment, Joint Center for Sustainable Forestry in

4 Southern China, Nanjing Forestry University, Nanjing 210037, P.R. China

$5{ }^{\mathrm{b}}$ Faculty of Natural Resource Management, Lakehead University, 955 Oliver Road,

6 Thunder Bay, ON P78 5E1, Canada

$7 \quad *$ Correspondence: Honghua Ruan (hhruan@ njfu.edu.cn)

8

9 Abbreviations: ABA, abscisic acid; APX, ascorbate peroxidase; AsA, ascorbate; Car, carotenoid; CAT, catalase; Chl, chlorophyll; EA, enzymatic antioxidants; EL, electrolyte leakage; Fv/Fm, maximal efficiency of PSII photochemistry; GR, glutathione reductase; MDA, malondialdehyde; NEA, non-enzymatic antioxidants; PMP, plasma membrane permeability; POD, peroxidase; PS, photosynthesis; $\mathrm{qP}$, photochemical quenching coefficient; ROS, reactive oxygen species; SD, standard deviation; SOD, superoxide dismutase.

One senence summary: The overproduction of ROS was the primary mechanism of plants in response to water stress and that plants tend to acclimate to water stress over time to some extent.

Short title: Plants respond to water stress

Y. S., and H. R. conceived the study; Y. S. performed the meta-analysis, and wrote the first draft; C. W., helped to collect and process the data; H. C., and H. R. contributed to the interpretation of data and manuscript revisions.

This work was supported by the National Key Research and Development Program of China (No. 2016YFD0600204) and the Priority Academic Program Development of Jiangsu Higher Education Institutions (PAPD). 


\section{Abstract}

30 Plants are key to the functionality of many ecosystem processes. The duration and

31 intensity of water stress are anticipated to increase in the future; however, an

32 elucidation of the responses of plants to water stress remains incomplete. For this

33 study, we present a global meta-analysis derived from 1301 paired observations from

3484 studies to evaluate the response patterns and mechanisms of plants to water stress.

35 The results revealed that while water stress inhibited plant growth and photosynthesis,

36 reactive oxygen species (ROS), plasma membrane permeability, enzymatic

37 antioxidants, and non-enzymatic antioxidants increased. These responses generally

38 increased with the intensity of water stress but were mitigated with experimental

39 duration. Our findings suggested that the overproduction of ROS was the primary

40 mechanism of plants in response to water stress and that plants tend to acclimate to

41 water stress over time to some extent. Our synthesis provides a framework for

42 understanding the responses and mechanisms of plants under drought conditions.

\section{KEYWORDS}

44 Water stress, plants, meta-analysis, reactive oxygen species, drought adaption 
45

\section{Introduction}

Drought is expected to increase continuously and significantly by the end of this century (Choat et al., 2012; IPCC, 2013). Water stress is problematic for plant growth and development (McDowell et al., 2011), as it limits access to resources required for photosynthesis due to stomatal closure and reduced internal water transport (Breda et al., 2006). As such, water stress impairs normal plant functionality and further induces morphological, physiological, and biochemical changes to compensate for water limitations (Mitchell et al., 2013; Lee et al., 2016).

Understanding the patterns and mechanisms of responses by plants to water stress is central to predicting future plant functionality and resilience to drought episodes.

The impacts of water stress on plant growth, physiology, and biochemistry are well documented, and numerous individual studies have examined the roles of plant physiological indexes as relates to their tolerance to water stress (van der Molen et al., 2011; Zwicke et al., 2015). For plants, water limitations lead to the overproduction of reactive oxygen species (ROS), such as hydrogen peroxide $\left(\mathrm{H}_{2} \mathrm{O}_{2}\right)$, and superoxide anion radical $\left(\mathrm{O}_{2}^{\overline{ }}\right)$, which results in growth inhibition (Wallace et al., 2016), decreases in photosynthetic functions (Deeba et al., 2012), lipid peroxidation, and further programmed cell death processes (Gill and Tuteja, 2010). However, to adapt to water stress, plants have evolved many acclimation mechanisms, including osmotic adjustment and antioxidant defense systems, which may enhance their ability to grow and develop under drought conditions (Fu and Huang, 2001; Khaleghi et al., 2019). Under water stress conditions, soluble sugars and proline accumulate to serve as osmolytes in various plants, assist in membrane protein stabilization, and ultimately increase plant resistance against water stress (Ashraf and Foolad, 2007; Gomes et al., 2010; Per et al., 2017). Further, ROS scavenging enzymatic antioxidants, such as 
superoxide dismutase (SOD), peroxidase (POD), catalase (CAT), glutathione reductase (GR), and ascorbate peroxidase (APX) can be activated to clear these excessive ROS (Gill and Tuteja, 2010). Adjustments in the activities of these enzymes are likely the primary path in plants for tolerating water stress (Nikoleta-Kleio et al., 2020).

The challenge remains to comprehensively address how various plants respond to water stress, as this can vary considerably (Rigui et al., 2019). For example, the ROS in leaves may increase (Tang et al., 2017) or decrease (Saglam et al., 2011) under water stress. Similarly, water stress can enhance (Sedaghat et al., 2017) or depress (Zhang et al., 2017) the SOD activity of plants. Previous studies have revealed that the performance of plant responses to water stress may decrease with experimental intensity and duration (Schneider et al., 2018), and vary with different plant species and tissues (Mirzaee et al., 2013; Lum et al., 2014). Therefore, it was necessary to conduct a systematic analysis to summarize the responses of plants under water stress.

The meta-analysis is a statistical methodology for synthesizing results across studies to reach an overall understanding of a problem (Gurevitch et al., 2018). A recent meta-analysis has specifically addressed the responses of plants to drought stress (Dong et al., 2017), but they focused on the physiological indexes (i.e., plant height, proline, electrolyte leakage, and root length) associated with transcription factors C-repeat/dehydration-responsive element-binding proteins which play important roles in plant response to environmental perturbations. Here we focus on the responses of ROS and enzymatic antioxidants (SOD, POD, CAT, GR, and APX), which represent defense mechanisms for plants under abiotic stresses (Gill and Tuteja, 2010; Sun et al., 2019). For this study, we established a global dataset by retrieving 

published papers to January 2020, including 1301 water-stress experiments from 84 papers (Table S1). Our objectives were to explore the general patterns and mechanisms of plants to water stress with the aim of providing reliable physiological indexes for the screening of drought-resistant species in the future.

\section{Materials and Methods}

\subsection{Data collection}

The database utilized in this meta-analysis was collected from peer-reviewed publications (Table S1) via the Web of Science and Google Scholar, prior to February 2020. The publication screening process is provided in Fig. S1. Our search terms were "water stress" or "water reduction", or "drought" and "plant". The following criteria were applied in this investigation: (1) Water stress and control groups began under the same abiotic and biotic conditions. (2) If the experiment included additional treatments, data were selected from the control and water stress groups only. (3) The water stress manipulation technique and duration had to be reported. (4) The sample sizes and means for the control and treatment groups were directly reported or could be extracted using WebPlotDigitizer (Burda et al., 2017). Our final dataset included 1301 paired observations from 84 primary articles (Fig. 1).

Eighteen physiological indexes, including abscisic acid (ABA), ascorbate peroxidase (APX), ascorbate (AsA), carotenoid (Car), CAT, chlorophyll (Chl), dry weight, electrolyte leakage (EL), maximal efficiency of PSII photochemistry (Fv/Fm), glutathione reductase (GR), malondialdehyde (MDA), POD, proline, protein, photochemical quenching coefficient (qP), ROS, SOD, and soluble sugar were collected. Specifically, we combined different indexes into specific plant performance, i.e., dry weight and protein into growth; Chl, Fv/Fm, and qP into photosynthesis (PS); ROS, MDA, and EL into plasma membrane permeability (PMP); 
APX, CAT, POD, SOD, and GR into enzymatic antioxidants (EA); and proline,

soluble sugar, ABA, AsA, and Car into non-enzymatic antioxidants (NEA) based on independent variables that might affect these responses variables were also collected, encompassing plant tissues tested indexes (whole plant, leaf, shoots, and roots), a mean water stress intensity of $0.52(0.05-0.88)$, and a mean experimental duration of since the experiment.

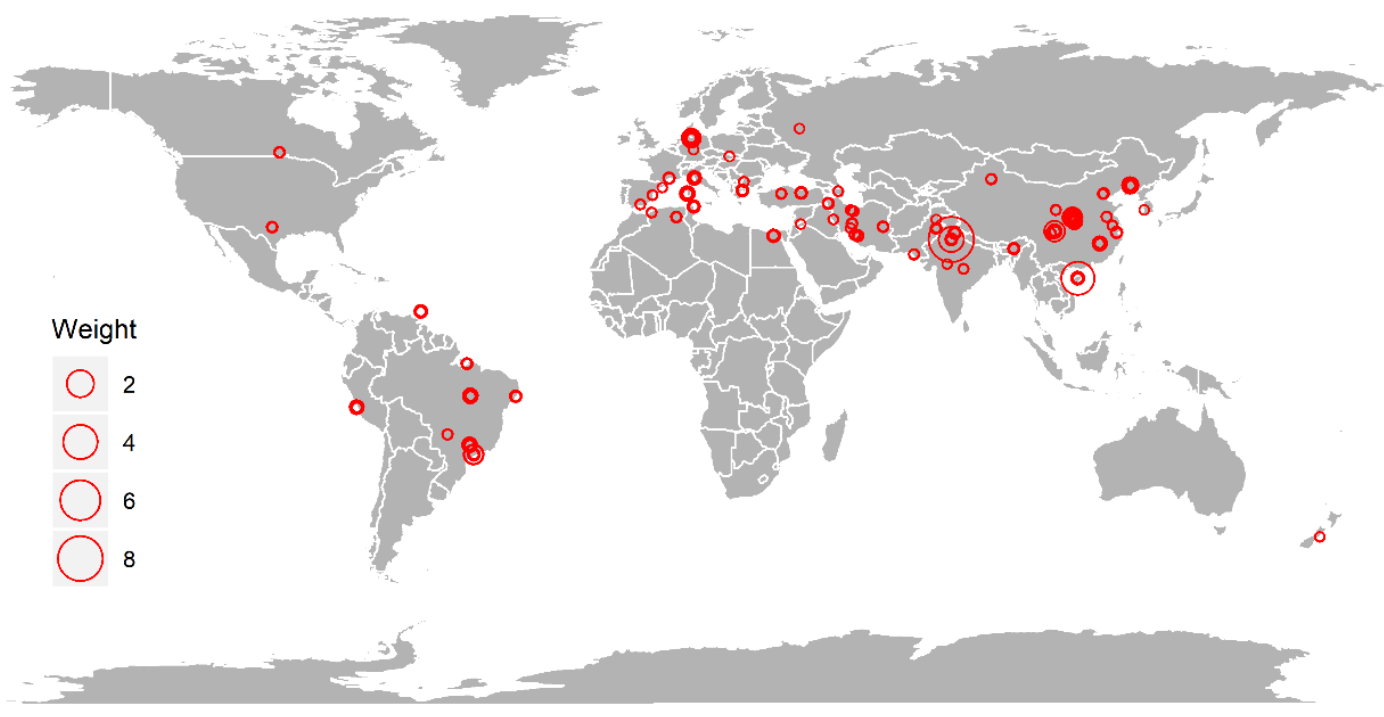

131 Figure 1. Geographic distribution of sites, with dot sizes representing study weight.

\subsection{Statistical analyses}

We employed natural log response ratios (lnRR) as effect sizes (Hedges et al., 1999) $\left(X_{i} / X_{c}\right)=\ln X_{i}-\ln X_{c}$, where $X_{i}$ and $X_{c}$ are the mean values for the water stress and control groups, respectively. The lnRR was weighted by the reciprocal of sampling variance, which was calculated as $\ln \left[\left(1 / n_{i}\right) \times\left(S_{i} / X_{i}\right)^{2}+\left(1 / n_{c}\right) \times\left(S_{c} / X_{c}\right)^{2}\right]$ using the $R$ 
package metafor 2.1 .0 (Viechtbauer, 2010), where $S_{\mathrm{i}}$ and $\mathrm{S}_{\mathrm{c}}$ represent the standard deviations of the water stress and control groups, respectively, with $n_{i}$ and $n_{c}$ as sample sizes. In instances where the standard deviations (SD) were not reported (a total of 86 observations) we imputed them using the "Bracken 1992" method (Benitez-Lopez et al., 2017; Sun et al., 2019) with metagear (Lajeunesse, 2016). For each plant parameter, we used the following linear mixed-effect model to test whether the mean $\operatorname{lnRR}$ differed from zero:

$$
\operatorname{lnRR}=\beta_{0}+\beta_{1} \ln (\mathrm{I})+\beta_{2} \ln (\mathrm{D})+\pi_{s t u d y}+\varepsilon
$$

where I and D represent the water stress intensity and experimental duration. $\beta_{n}$, $\pi_{\text {study }}$, and $\varepsilon$ are the coefficients to be calculated, the random effect factor of "Study", and sampling error, respectively. We applied linear mixed-effects models using the restricted maximum likelihood estimation with the lme4 package (Bates et al., 2015). Continuous predictors including water stress intensity and experimental duration in Equation (1) were scaled (observed minus mean and divided by one SD). To examine the linearity assumption between dependent and independent variables, we compared the logarithmic and linear functions for I and D using the MuMIn package (Bartoń, 2018), and found that the logarithmic functions for I and D resulted in lower, or similar, Akaike information criterion (AIC) values (Table S2). For consistency, we analyzed variables with Equation (1).

To maximize the comparability, we tested the effects of plant performances and tissues on $\ln R R$ by adding plant performances, and tissues to Equation (1). For ease of interpretation, we transformed the $\ln R R$ and its corresponding confidence interval $(\mathrm{CI})$ using $[\exp (\operatorname{lnRR})-1] \times 100 \%$. Further, linear-regressions were employed to examine the correlations of index ratio responses with water stress intensity and experimental duration. All statistical analyses were performed using R 3.6.0 software 
162

163

164

165

166

167

168

169

170

171

172

173

174

175

176

177

178

179

180

181

182

183

184

185

(R Development Core Team, 2019).

\section{Results}

Across all individual studies, the ABA increased significantly, by $126.6 \%$ on average (CI, 26.9-226.3\%; $P=0.01)$, AsA by $19.3 \%(9.1-29.5 \% ; P<0.01)$, CAT by $28.8 \%$

$(14.3-43.4 \%, P<0.01)$, EL by $99.4 \%(45.9-153.0 \%, P<0.01)$, MDA by $44.2 \%$

(19.9-68.5\%, $P<0.01)$, POD by $28.0 \%(11.7-44.2 \%, P<0.01)$, proline by $136.8 \%$

(59.9-213.7\%, $P<0.001)$, ROS by $65.7 \%(33.8-97.6 \%, P<0.001)$, SOD by $29.8 \%$

$(15.4-44.1 \%, P<0.001)$, and soluble sugar by $116.9 \%(32.2-201.5 \%, P=0.03)$ under

water stress, compared to the mean of the control groups (Fig. 2). However, on

average, water stress significantly $(P<0.05)$ decreased Chl by $32.5 \%$, dry weight by

$37.4 \%, \mathrm{Fv} / \mathrm{Fm}$ by $13.1 \%$, and qP by $50.2 \%$, but had no significant impacts on APX,

Car, GR, and protein (all $P>0.05$; Fig. 2).

We found that the effect sizes for EA, NEA, and PMP increased significantly under water stress (all $P<0.001$ ), and the effect size for growth and PS decreased (all $P<0.001$; Fig. 3a). Furthermore, for plant tissues tested indexes, water stress had positive effects on leaves $(16.9 \%, P<0.01)$, negative effects on shoots $(-37.5 \%, P<$ 0.001), but no effects on the whole plants and roots (all $P>0.05$; Fig. 3b).

With increasing water stress intensity, the effect size for ABA, CAT, EL, MDA, proline, and SOD increased significantly (all $P<0.05$ ), whereas the effect size for Chl decreased $(P<0.01$; Fig. 4). The effect sizes for APX, Chl, MDA, and SOD decreased significantly with experimental duration (all $P<0.05$ ), and the effect size for AsA, EL, and protein increased (all $P<0.01$; Fig. 5). The effect sizes for EA, NEA, and PMP increased significantly with water stress intensity (all $P<0.01$; Fig. 6), and PMP decreased significantly with experimental duration $(P<0.001$; Fig. 7). 


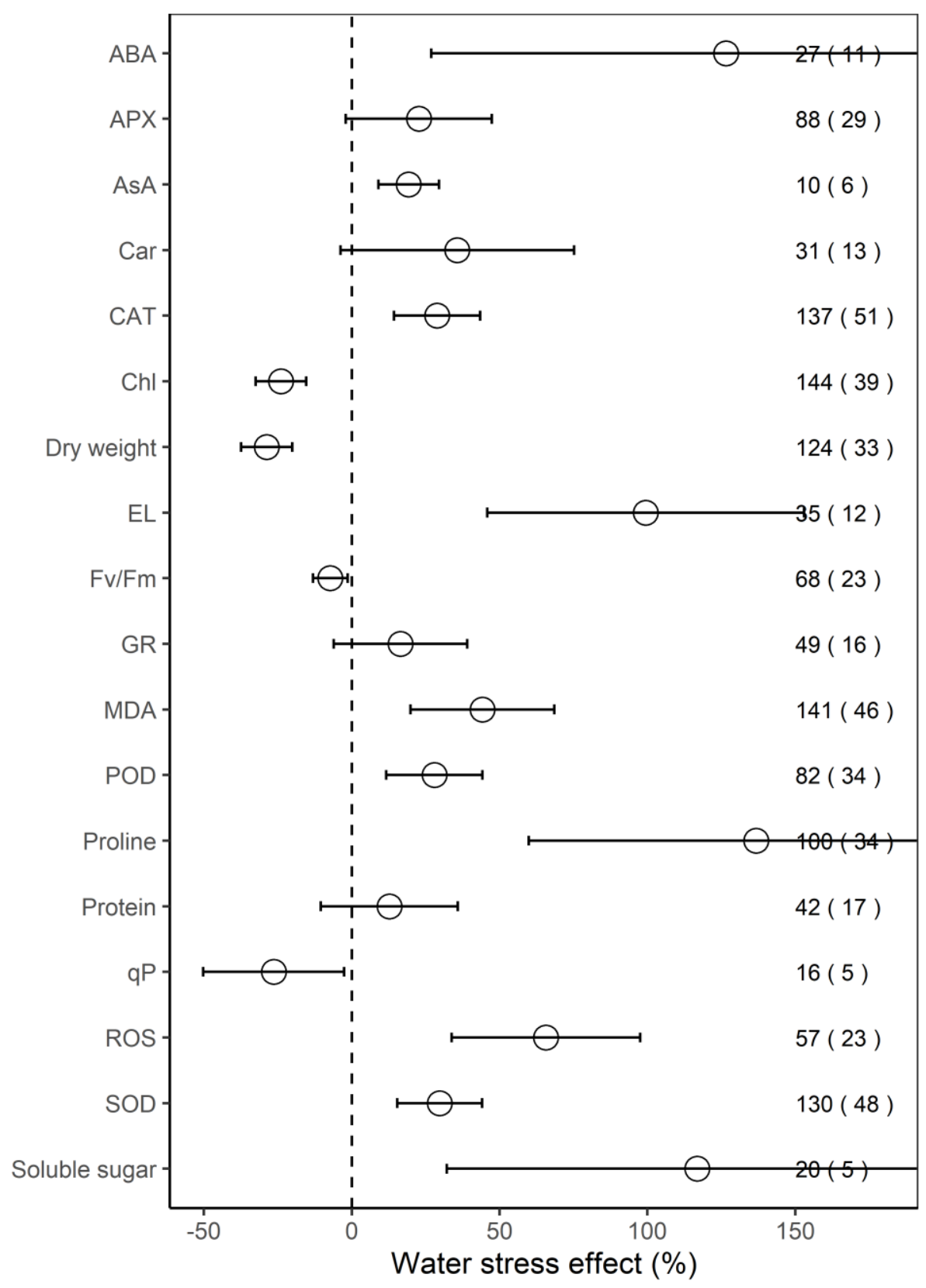

188 Figure 2. The response of physiological indexes to water stress. Values are the means and $18995 \%$ confidence intervals. The dashed black line is zero effect size. Numbers without and

190 within parentheses represent the number of observations and studies, respectively. ABA,

191 APX, AsA, Car, CAT, Chl, EL, Fv/Fm, GR, MDA, POD, qP, ROS, and SOD represent

192 abscisic acid, ascorbate peroxidase, ascorbate, carotenoid, catalase, chlorophyll, electrolyte

193 leakage, maximal efficiency of PSII photochemistry, glutathione reductase, malondialdehyde,

194 peroxidase, photochemical quenching coefficient, reactive oxygen species, and superoxide

195 dismutase, respectively. 
(a)

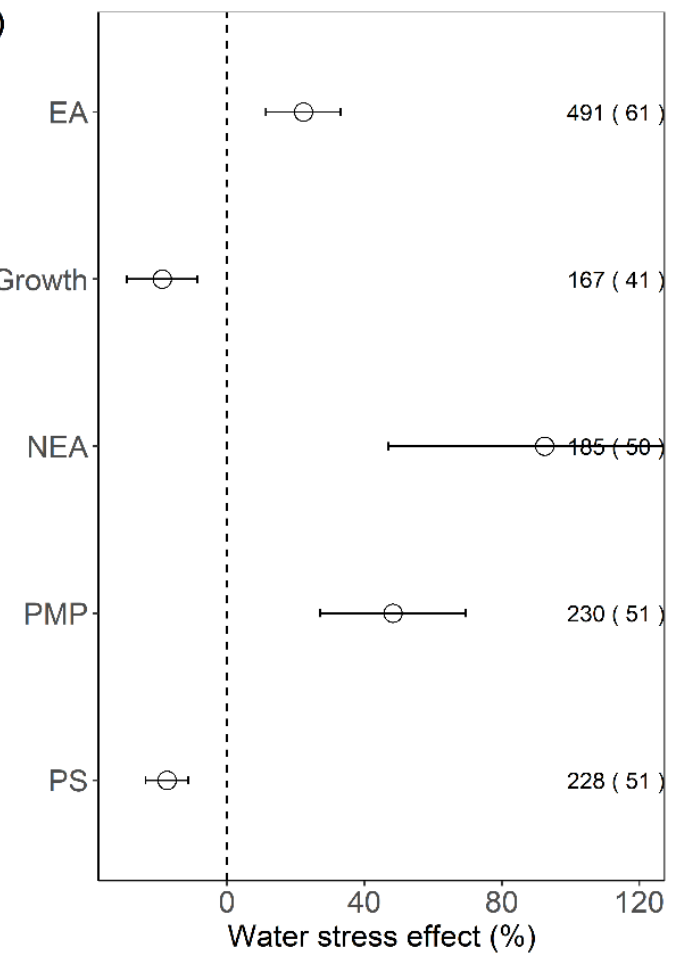

(b)

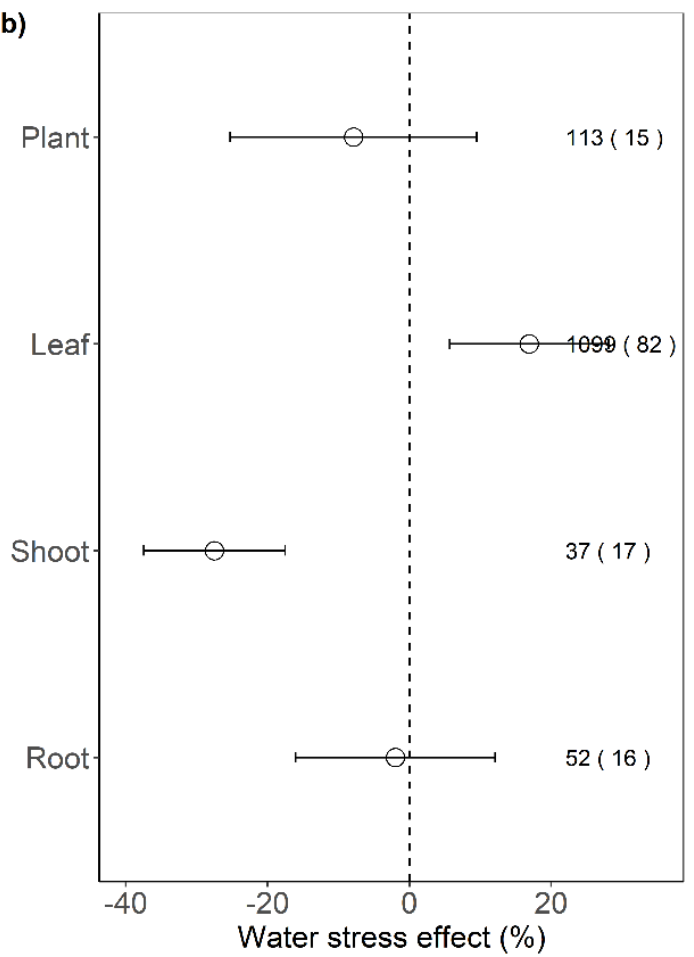

197 Figure 3. The response of plant performance (a) and tissues (b) to water stress. Values are

198 means and 95\% confidence intervals. Dashed black line is zero effect size. Numbers without

199 and within parentheses represent the number of observations and studies, respectively. EA,

200 NEA, PMP, and PS represent enzymatic antioxidants, non-enzymatic antioxidants, plasma

201 membrane permeability, and photosynthesis, respectively. 

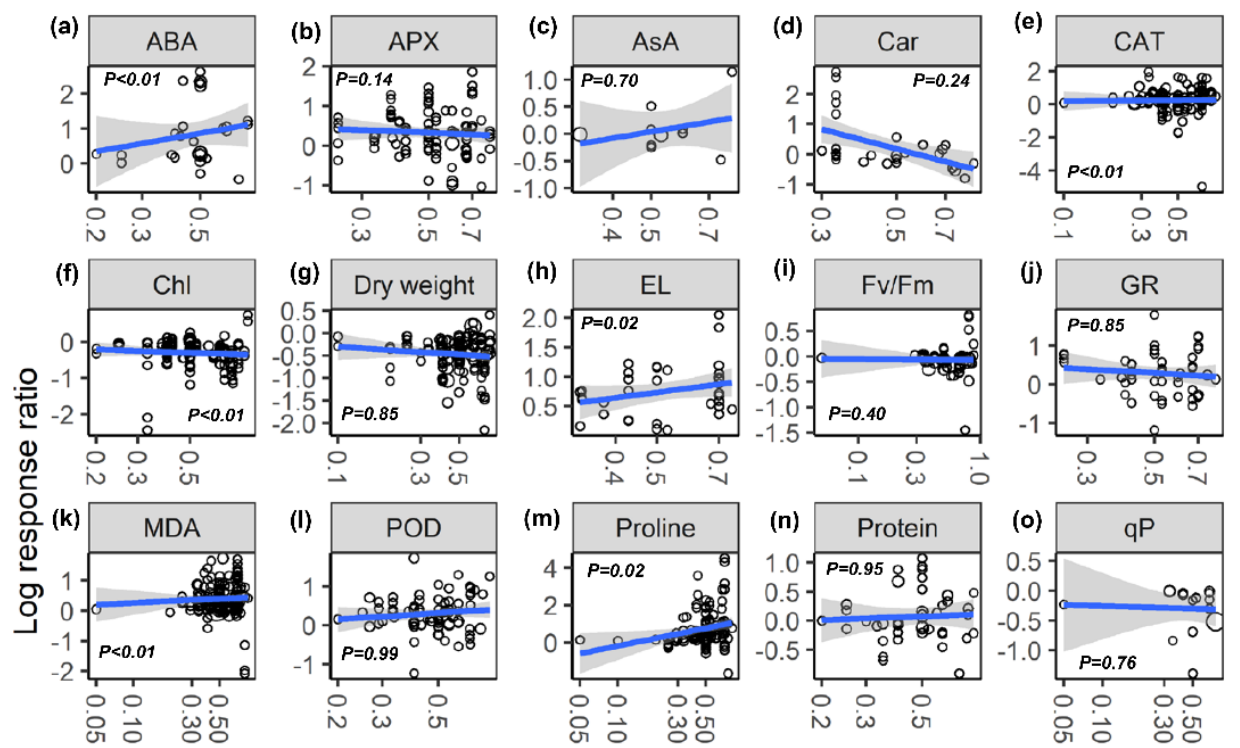

Weight
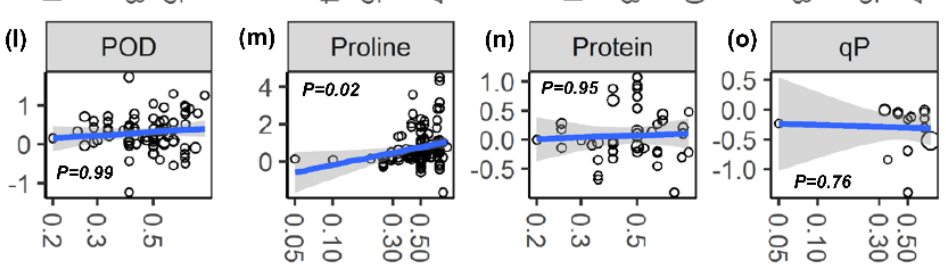

$\bigcirc 2$

4

6

O 8
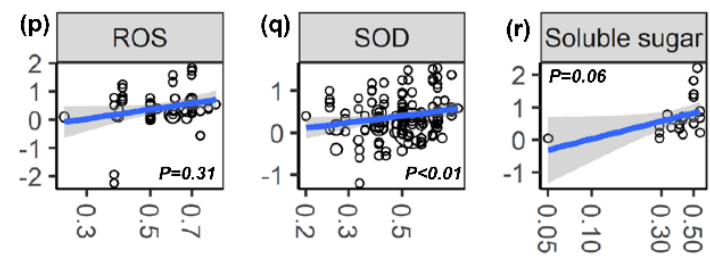

Water stress intensity

Figure 4. The responses of effect sizes of ABA (a), APX (b), AsA (c), Car (d), CAT (e), Chl (f), dry weight (g), EL (h), Fv/Fm (i), GR (g), MDA (k), POD (l), proline (m), protein (n), qP (o), ROS (p), SOD (q), and soluble sugar (r) to water stress intensity. Linear regressions are

206 shown as solid blue lines, and 95\% confidence intervals are the shaded areas. Circle sizes are proportional to the sampling variances. See Fig. 2 for abbreviations. 
bioRxiv preprint doi: https://doi.org/10.1101/2020.03.02 973610; this version posted March 4, 2020. The copyright holder for this preprint (which was not certified by peer review) is the author/funder, who has granted bioRxiv a license to display the preprint in perpetuity. It is made available under aCC-BY-NC-ND 4.0 International license.
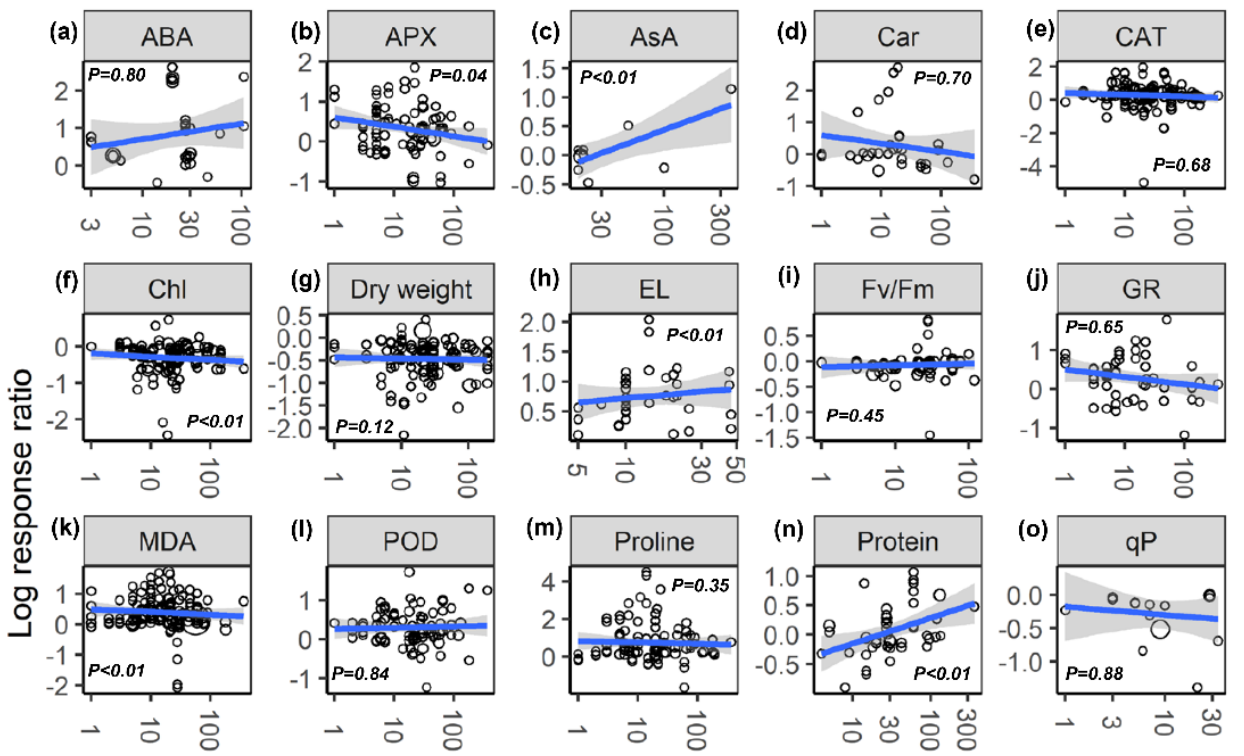

Weight

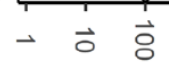

$\bigcirc 2$
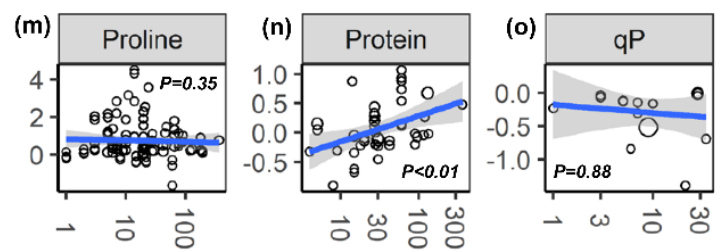

○ 4

○ 6

○ 8
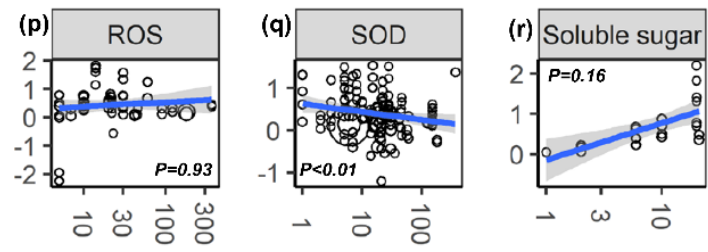

Experimental duration (days)

209 Figure 5. The responses of effect sizes of ABA (a), APX (b), AsA (c), Car (d), CAT (e), Chl 210 (f), dry weight (g), EL (h), Fv/Fm (i), GR (g), MDA (k), POD (l), proline (m), protein (n), qP 211 (o), ROS (p), SOD (q), and soluble sugar (r) to experimental duration. Linear regressions are 212 shown as solid blue lines, and 95\% confidence intervals are the shaded areas. Circle sizes are 213 proportional to the sampling variances. See Fig. 2 for abbreviations. 


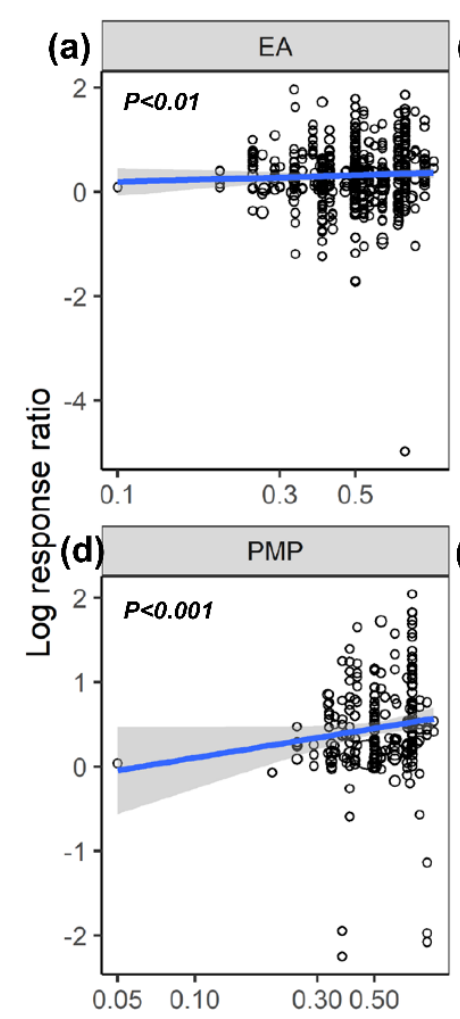

214

215 Figure 6. The responses of effect sizes of EA (a), growth (b), NEA (c), PMP (d), and PS (e)

216 to water stress intensity. Linear regressions are shown as solid blue lines, and 95\% confidence

217 intervals are the shaded areas. Circle sizes are proportional to the sampling variances. EA,

218 NEA, PMP, and PS represent enzymatic antioxidants, non-enzymatic antioxidants, plasma
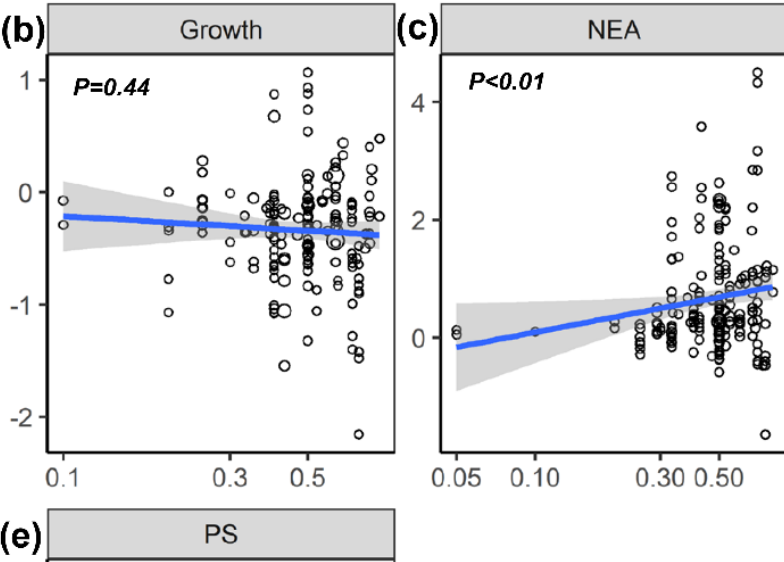

Weight

O 2

$\bigcirc 4$

$\bigcirc 6$

8

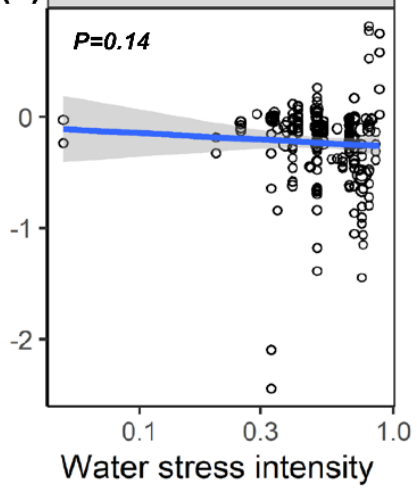

(1) 

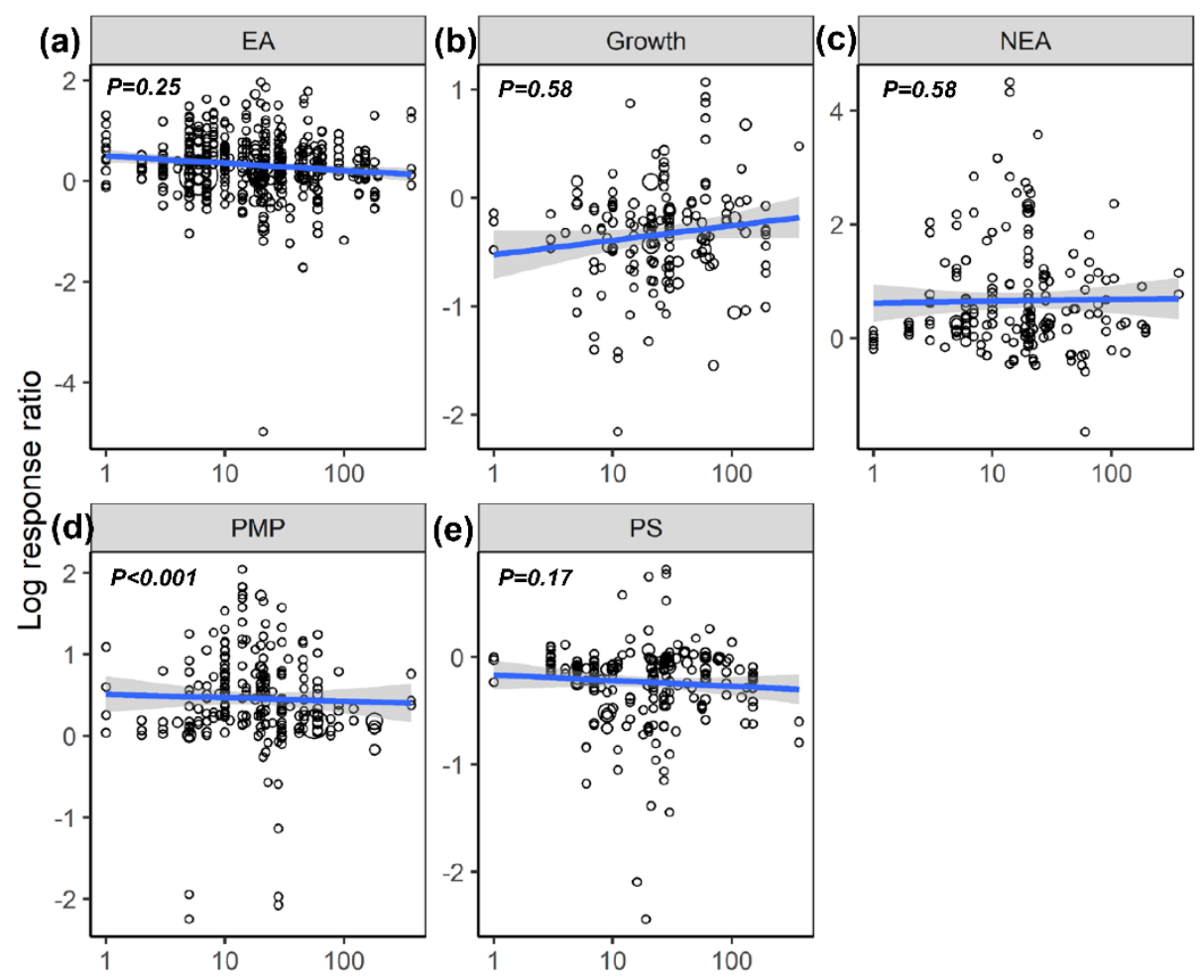

Weight

$\bigcirc 2$

$\bigcirc 4$

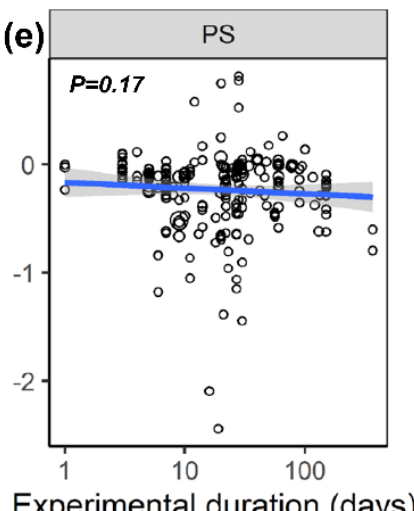

Experimental duration (days)

221 Figure 7. The responses of effect sizes of EA (a), growth (b), NEA (c), PMP (d), and PS (e) experimental duration. Linear regressions are shown as solid blue lines and 95\% confidence intervals are the shaded areas. Circle sizes are proportional to the sampling variances. See Fig. 6 for abbreviations. 


\section{Discussion}

226 The current meta-analysis based on 1301 observations, is the first to integrally examine the response patterns and mechanisms of plants to water stress on a global scale. A consistent and general response pattern of plants to water stress was found; these responses increased with water stress intensity but were mitigated with experimental duration. Below, we elaborate on the potential mechanisms for the

231 observed patterns and conclude with suggestions for future research.

\subsection{Mechanisms behind plant responses}

233 As anticipated, our analysis revealed that water stress significantly inhibited plant

234 growth and photosynthesis (Figs. 2, 3a). Further, we found that the negative response 235 of Chl to water stress was more pronounced with increasing intensity and duration 236 (Figs. 4f, 5f). This suggests that $\mathrm{Chl}$ is very sensitive to water stress among various 237 types of plants. The probable explanation is that water stress can damage 238 photosynthetic organs and alter leaf structures, thereby reducing the photosynthetic 239 activities of plants and affecting plant growth (Aranjuelo et al., 2011).

241 indicated a malfunction of the plasma membrane (Murray et al., 1989; Bouchemal et 242 al., 2016) and lipid peroxidation (Sun et al., 2019), respectively. Our meta-analysis 243 demonstrated that water stress significantly increased EL, MDA, ROS (Fig. 2), and 244 stimulated PMP (Fig. 3a), which suggested that membrane damage occurred under 245 water stress. Schneider et al. (2018) reported that high concentrations of ROS in 246 plants are highly toxic to lipids and resulted in oxidative stress. Together, these results 247 indicated that the overproduction of ROS was the primary mechanism of water stress.

248 We also found that MDA and PMP exhibited positive responses to intensity, but 249 negative responses to duration (Figs. 4k, 5k, 6d, 7d). One possible explanation is that 
plants have evolved some strategies to adapt to water stress (see the discussion below)

251 (Anjum et al., 2012; Sperdouli and Moustakas, 2012). While increases in the EL of

252 plant cells to both intensity and duration were observed (Figs. 4h, 5h), this index

253 should be useful in screening for drought-resistant species.

Our study offers new insights into the increase of EA being associated with scavenged ROS under water stress (Figs. 2, 3a, 6a). Although CAT, POD, and SOD activities were higher under water stress than the control, both APX and GR did not the Halliwell-Asada pathway may work less efficiently than CAT, POD, and SOD, likely because various enzymes located within different cellular compartments have disparate functions (Mittler, 2002; Gill and Tuteja, 2010; Sun et al., 2019). Further, the CAT and SOD increased with intensity (Figs, 4e, q), being attributed to the metabolic processes (Schneider et al., 2018). Thus, we recommend that the kinetics involved in the enzymatic responses to water stress should be investigated in future experiments.

267 (Figs. 2, 3a) under water stress. We also found that the positive responses of ABA, 268 proline, and NEA were more pronounced with intensity (Figs. 4, 6c), which suggested 269 that $\mathrm{ABA}$ and proline were sensitive plant parameters to water stress. Higher concentrations of ABA acted to adapt to water stress (Belkheiri and Mulas, 2013),

271 where increased proline accumulation was considered to mitigate the adverse effects 272 of ROS (Chen and Dickman, 2005). Interestingly, plant roots were not significantly 273 impacted by water stress (Fig. 3b). One possible explanation is that increases in the 274 numbers of root ducts improved the efficacy of water transport; thus assisting plants 
to resist water stress (Lee et al., 2016).

\subsection{Suggestions for future experiments}

We encountered two important inconsistencies in our meta-analysis across studies. Firstly, only 10 studies of the 84 in our dataset lasted more than three months. Experimental duration is a vital factor that affects plant responses to water stress (Figs. $5,7)$; therefore, we suggest that longer time scales (> three months) be employed in future experiments. Secondly, as with several ecological meta-analyses, we found a hemispheric bias in our knowledge of the effects of water stress on plants (Feeley et al., 2017). Most observations were derived from experiments performed at a latitude of $>19.3^{\circ}$ in the Northern Hemisphere (only nine studies were conducted in the Southern Hemisphere). Therefore, we are hopeful that our study will motivate new publications in underrepresented regions (Fig. 1).

\section{Conclusion}

In conclusion, our meta-analysis, which employed a global empirical dataset for the responses of plants to water stress, revised the previous notion that water stress inhibits plant growth (Schneider et al., 2018). Divergent responses of Chl, EL, and ROS were partly explained by the inhibition of plant growth. Water stress affected plant performance primarily through the overproduction of ROS, which led to plasma membrane damage. Meanwhile, a variety of physiological indexes, i.e., CAT, SOD, $\mathrm{ABA}$, and proline were activated to control the levels of cellular ROS to compensate for water stress. These above indexes were evaluated to facilitate screening for drought-resistant species. Further, the effects of water stress were observed to be more pronounced with intensity, which was, however, mitigated with duration. Therefore, imbuing plants with the capacity to scavenge excessive ROS will be useful in the future to facilitate their endurance during drought events. 


\section{Declaration of Interest Statement}

301 None.

\section{Appendix A. Supplementary data}

303 Additional supporting information that accompanies this paper may be found in the

304 online version of this article.

305 All data and R codes will be published on figshare once the manuscript is accepted for 306 publication.

\section{References}

Anjum S, Farooq M, Xie X-y, Liu X-j, ljaz M (2012) Antioxidant defense system and proline accumulation enables hot pepper to perform better under drought. Scientia Horticulturae 140: 66-73

Aranjuelo I, Molero G, Erice G, Avice JC, Nogués S (2011) Plant physiology and proteomics reveals the leaf response to drought in alfalfa (Medicago sativa L.). Journal of Experimental Botany 62: 111-123

Ashraf M, Foolad MR (2007) Roles of glycine betaine and proline in improving plant abiotic stress resistance. Environmental and Experimental Botany 59: 206216

Bartoń K (2018) MuMln: Multi-model inference. R package version 1.42.1. Available at: http://CRAN.R-project.org/package=MuMIn.

Bates D, Machler M, Bolker BM, Walker SC (2015) Fitting Linear Mixed-Effects Models Using Ime4. Journal of Statistical Software 67: 1-48

Belkheiri O, Mulas M (2013) Effect of water stress on growth, water use efficiency and gas exchange as related to osmotic adjustment of two halophytes Atriplex spp. Functional Plant Biology 40: 466

Benitez-Lopez A, Alkemade R, Schipper AM, Ingram DJ, Verweij PA, Eikelboom JAJ, Huijbregts MAJ (2017) The impact of hunting on tropical mammal and bird populations. Science 356: 180-183

\section{Bouchemal K, Bouldjadj R, Belbekri MN, Ykhlef N, Djekoun A (2016) Differences in} antioxidant enzyme activities and oxidative markers in ten wheat (Triticum durumDesf.) genotypes in response to drought, heat and paraquat stress.

331 Breda N, Huc R, Granier A, Dreyer E (2006) Temperate forest trees and stands 
under severe drought: a review of ecophysiological responses, adaptation processes and long-term consequences. Annals of Forest Science 63: 625644

Burda BU, O'Connor EA, Webber EM, Redmond N, Perdue LA (2017) Estimating data from figures with a Web-based program: Considerations for a systematic review. Research Synthesis Methods 8: 258-262

Caverzan A, Casassola A, Brammer S (2016) Antioxidant responses of wheat plants under stress. Genetics and Molecular Biology 39: 1-6

Chen C, Dickman M (2005) Proline suppresses apoptosis in the fungal pathogen Colletotrichum trifolii. Proceedings of the National Academy of Sciences of the United States of America 102: 3459-3464

Choat B, Jansen S, Brodribb TJ, Cochard H, Delzon S, Bhaskar R, Bucci SJ, Feild TS, Gleason SM, Hacke UG, Jacobsen AL, Lens F, Maherali H, MartinezVilalta J, Mayr S, Mencuccini M, Mitchell PJ, Nardini A, Pittermann J, Pratt RB, Sperry JS, Westoby M, Wright IJ, Zanne AE (2012) Global convergence in the vulnerability of forests to drought. Nature 491: 752-755

Deeba F, Pandey AK, Ranjan S, Mishra A, Singh R, Sharma YK, Shirke PA, Pandey V (2012) Physiological and proteomic responses of cotton (Gossypium herbaceum L.) to drought stress. Plant Physiology and Biochemistry 53: 6-18

Dong C, Ma Y, Wisniewski M, Cheng Z-M (2017) Meta-analysis of the effect of overexpression of CBF/DREB family genes on drought stress response. Environmental and Experimental Botany 142: 1-14

Feeley KJ, Stroud JT, Perez TM, Kühn I (2017) Most 'global' reviews of species' responses to climate change are not truly global. Diversity and Distributions 23: $231-234$

Fu JM, Huang BR (2001) Involvement of antioxidants and lipid peroxidation in the adaptation of two cool-season grasses to localized drought stress. Environmental and Experimental Botany 45: 105-114

Gill SS, Tuteja N (2010) Reactive oxygen species and antioxidant machinery in abiotic stress tolerance in crop plants. Plant Physiology and Biochemistry 48: 909-930

Gomes FP, Oliva MA, Mielke MS, Almeida AAF, Aquino LA (2010) Osmotic adjustment, proline accumulation and cell membrane stability in leaves of Cocos nucifera submitted to drought stress. Scientia Horticulturae 126: 379384

Gurevitch J, Koricheva J, Nakagawa S, Stewart G (2018) Meta-analysis and the 
science of research synthesis. Nature 555: 175-182

Hedges LV, Gurevitch J, Curtis PS (1999) The meta-analysis of response ratios in experimental ecology. Ecology 80: 1150-1156

IPCC (2013) Climate Change 2013: The Physical Science Basis, Contribution of Working Group I to the Fifth Assessment Report of the Intergovernmental Panel on Climate Change. Cambridge University Press, Cambridge, UK.

Khaleghi A, Naderi R, Brunetti C, Maserti BE, Salami SA, Babalar M (2019) Morphological, physiochemical and antioxidant responses of Maclura pomifera to drought stress. Sci Rep 9: 19250

Lajeunesse MJ (2016) Facilitating systematic reviews, data extraction and metaanalysis with the metagear package for $r$. Methods in Ecology and Evolution 7: 323-330

Lee DK, Jung H, Jang G, Jeong JS, Kim YS, Ha SH, Do Choi Y, Kim JK (2016) Overexpression of the OsERF71 Transcription Factor Alters Rice Root Structure and Drought Resistance. Plant Physiology 172: 575-588

Lum MS, Hanafi MM, Rafii YM, Akmar ASN (2014) Effect of Drought Stress on Growth, Proline and Antioxidant Enzyme Activities of Upland Rice. Journal of Animal and Plant Sciences 24: 1487-1493

McDowell NG, Beerling DJ, Breshears DD, Fisher RA, Raffa KF, Stitt M (2011) The interdependence of mechanisms underlying climate-driven vegetation mortality. Trends in Ecology \& Evolution 26: 523-532

Mirzaee M, Moieni A, Ghanati F (2013) Effects of Drought Stress on the Lipid Peroxidation and Antioxidant Enzyme Activities in Two Canola (Brassica napus L.) Cultivars. Journal of Agricultural Science and Technology 15: 593602

Mitchell PJ, O'Grady AP, Tissue DT, White DA, Ottenschlaeger ML, Pinkard EA hydraulic dysfunction and carbohydrate depletion during tree mortality. New Phytologist 197: 862-872

Mittler R (2002) Oxidative Stress, Antioxidants and Stress Tolerance. Trends in plant science 7: 405-410

Murray MB, Cape JN, Fowler D (1989) Quantification of Frost Damage in Plant Tissues by Rates of Electrolyte Leakage. The New Phytologist 113: 307-311 
404

405

406

407

408

409

410

411

412

413

414

415

416

417

418

419

420

421

422

423

424

425

426

427

428

429

430

431

432

433

434

435

436

437

438

439

11

Per TS, Khan NA, Reddy PS, Masood A, Hasanuzzaman M, Khan MIR, Anjum NA (2017) Approaches in modulating proline metabolism in plants for salt and drought stress tolerance: Phytohormones, mineral nutrients and transgenics. Plant Physiology and Biochemistry 115: 126-140

R Development Core Team (2019) R: A language and environment for statistical computing. In, Ed 3.6.0. R Foundation for Statistical Computing, Vienna, Austria, http://www.Rproject.org/

Rigui AP, Carvalho V, Wendt Dos Santos AL, Morvan-Bertrand A, Prud'homme MP, Machado de Carvalho MA, Gaspar M (2019) Fructan and antioxidant metabolisms in plants of Lolium perenne under drought are modulated by exogenous nitric oxide. Plant Physiol Biochem 145: 205-215

Saglam A, Saruhan N, Terzi R, Kadioglu A (2011) The relations between antioxidant enzymes and chlorophyll fluorescence parameters in common bean cultivars differing in sensitivity to drought stress. Russian Journal of Plant Physiology 58: $60-68$

Schneider JR, Caverzan A, Chavarria G (2018) Water deficit stress, ROS involvement, and plant performance. Archives of Agronomy and Soil Science 65: $1160-1181$

Sedaghat M, Tahmasebi-Sarvestani Z, Emam Y, Mokhtassi-Bidgoli A (2017) Physiological and antioxidant responses of winter wheat cultivars to strigolactone and salicylic acid in drought. Plant Physiology and Biochemistry 119: $59-69$

Sperdouli I, Moustakas M (2012) Interaction of proline, sugars, and anthocyanins during photosynthetic acclimation of Arabidopsis thaliana to drought stress. Journal of Plant Physiology 169: 577-585

Sun Y, Sun P, Wang C, Liao J, Ni J, Zhang T, Wang R, Ruan H (2019) Growth, physiological function, and antioxidant defense system responses of Lemna minor L. to decabromodiphenyl ether (BDE-209) induced phytotoxicity. Plant Physiol Biochem 139: 113-120

Sun Y, Wang C, Xu X, Ruan H (2019) Responses of plants to polybrominated diphenyl ethers (PBDEs) induced phytotoxicity: A hierarchical meta-analysis. Chemosphere 240: 124865

Tang YP, Sun X, Wen T, Liu MJ, Yang MY, Chen XF (2017) Implications of terminal oxidase function in regulation of salicylic acid on soybean seedling photosynthetic performance under water stress. Plant Physiology and 
van der Molen MK, Dolman AJ, Ciais P, Eglin T, Gobron N, Law BE, Meir P, Peters (2011) Drought and ecosystem carbon cycling. Agricultural and Forest Meteorology 151: 765-773

Viechtbauer W (2010) Conducting Meta-Analyses in R with the metafor Package. Journal of Statistical Software 36: 1-48

Wallace JG, Zhang XC, Beyene Y, Semagn K, Olsen M, Prasanna BM, Buckler ES (2016) Genome-wide Association for Plant Height and Flowering Time across 15 Tropical Maize Populations under Managed Drought Stress and WellWatered Conditions in Sub-Saharan Africa. Crop Science 56: 2365-2378

Zhang C, Li X, He YF, Zhang JF, Yan T, Liu XL (2017) Physiological investigation of sucrose metabolism is involved in the improved drought tolerance. Plant Physiology and Biochemistry 115: 328-342 


\section{Parsed Citations}

Anjum S, Farooq M, Xie X-y, Liu X-j, ljaz M (2012) Antioxidant defense system and proline accumulation enables hot pepper to perform better under drought. Scientia Horticulturae 140: 66-73

Pubmed: Author and Title

Google Scholar: Author Only Title Only Author and Title

Aranjuelo I, Molero G, Erice G, Avice JC, Nogués S (2011) Plant physiology and proteomics reveals the leaf response to drought in alfalfa (Medicago sativa L.). Journal of Experimental Botany 62: 111-123

Pubmed: Author and Title

Google Scholar: Author Only Title Only Author and Title

Ashraf M, Foolad MR (2007) Roles of glycine betaine and proline in improving plant abiotic stress resistance. Environmental and Experimental Botany 59: 206-216

Pubmed: Author and Title

Google Scholar: Author Only Title Only Author and Title

Bartoń K (2018) MuMln: Multi-model inference. R package version 1.42.1. Available at: http://CRAN.R-project.org/package=MuMIn.

Pubmed: Author and Title

Google Scholar: Author Only Title Only Author and Title

Bates D, Machler M, Bolker BM, Walker SC (2015) Fitting Linear Mixed-Effects Models Using Ime4. Journal of Statistical Software 67: 148

Pubmed: Author and Title

Google Scholar: Author Only Title Only Author and Title

Belkheiri O, Mulas M (2013) Effect of water stress on growth, water use efficiency and gas exchange as related to osmotic adjustment of two halophytes Atriplex spp. Functional Plant Biology 40: 466

Pubmed: Author and Title

Google Scholar: Author Only Title Only Author and Title

Benitez-Lopez A, Akemade R, Schipper AM, Ingram DJ, Verweij PA, Eikelboom JA, Huijbregts MAJ (2017) The impact of hunting on tropical mammal and bird populations. Science 356: 180-183

Pubmed: Author and Title

Google Scholar: Author Only Title Only Author and Title

Bouchemal K, Bouldjadj R, Belbekri MN, Ykhlef N, Djekoun A(2016) Differences in antioxidant enzyme activities and oxidative markers in ten wheat (Triticum durumDesf.) genotypes in response to drought, heat and paraquat stress. Archives of Agronomy and Soil

Science 63: 710-722

Pubmed: Author and Title

Google Scholar: Author Only Title Only Author and Title

Breda N, Huc R, Granier A, Dreyer E (2006) Temperate forest trees and stands under severe drought: a review of ecophysiological responses, adaptation processes and long-term consequences. Annals of Forest Science 63: 625-644

Pubmed: Author and Title

Google Scholar: Author Only Title Only Author and Title

Burda BU, O'Connor EA, Webber EM, Redmond N, Perdue LA(2017) Estimating data from figures with a Web-based program:

Considerations for a systematic review. Research Synthesis Methods 8: 258-262

Pubmed: Author and Title

Google Scholar: Author Only Title Only Author and Title

Caverzan A, Casassola A, Brammer S (2016) Antioxidant responses of wheat plants under stress. Genetics and Molecular Biology 39: 1-

6

Pubmed: Author and Title

Google Scholar: Author Only Title Only Author and Title

Chen C, Dickman M (2005) Proline suppresses apoptosis in the fungal pathogen Colletotrichum trifolii. Proceedings of the National

Academy of Sciences of the United States of America 102: 3459-3464

Pubmed: Author and Title

Google Scholar: Author Only Title Only Author and Title

Choat B, Jansen S, Brodribb TJ, Cochard H, Delzon S, Bhaskar R, Bucci SJ, Feild TS, Gleason SM, Hacke UG, Jacobsen AL, Lens F, Maherali H, Martinez-Vilalta J, Mayr S, Mencuccini M, Mitchell PJ, Nardini A, Pittermann J, Pratt RB, Sperry JS, Westoby M, Wright IJ,

Zanne AE (2012) Global convergence in the vulnerability of forests to drought. Nature 491: 752-755

Pubmed: Author and Title

Google Scholar: Author Only Title Only Author and Title

Deeba F, Pandey AK, Ranjan S, Mishra A, Singh R, Sharma YK, Shirke PA, Pandey V (2012) Physiological and proteomic responses of cotton (Gossypium herbaceum L.) to drought stress. Plant Physiology and Biochemistry 53: 6-18

Pubmed: Author and Title

Google Scholar: Author Only Title Only Author and Title

Dong C, Ma Y, Wisniewski M, Cheng Z-M (2017) Meta-analysis of the effect of overexpression of CBF/DREB family genes on drought 
stress response. Environmental and Experimental Botany 142: 1-14

Pubmed: Author and Title

Google Scholar: Author Only Title Only Author and Title

Feeley KJ, Stroud JT, Perez TM, Kühn I (2017) Most 'global' reviews of species' responses to climate change are not truly global. Diversity and Distributions 23: 231-234

Pubmed: Author and Title

Google Scholar: Author Only Title Only Author and Title

Fu JM, Huang BR (2001) Involvement of antioxidants and lipid peroxidation in the adaptation of two cool-season grasses to localized drought stress. Environmental and Experimental Botany 45: 105-114

Pubmed: Author and Title

Google Scholar: Author Only Title Only Author and Title

Gill SS, Tuteja N (2010) Reactive oxygen species and antioxidant machinery in abiotic stress tolerance in crop plants. Plant Physiology and Biochemistry 48: 909-930

Pubmed: Author and Title

Google Scholar: Author Only Title Only Author and Title

Gomes FP, Oliva MA, Mielke MS, Almeida AAF, Aquino LA(2010) Osmotic adjustment, proline accumulation and cell membrane stability in leaves of Cocos nucifera submitted to drought stress. Scientia Horticulturae 126: 379-384

Pubmed: Author and Title

Google Scholar: Author Only Title Only Author and Title

Gurevitch J, Koricheva J, Nakagawa S, Stewart G (2018) Meta-analysis and the science of research synthesis. Nature 555: 175-182

Pubmed: Author and Title

Google Scholar: Author Only Title Only Author and Title

Hedges LV, Gurevitch J, Curtis PS (1999) The meta-analysis of response ratios in experimental ecology. Ecology 80: 1150-1156

Pubmed: Author and Title

Google Scholar: Author Only Title Only Author and Title

IPCC (2013) Climate Change 2013: The Physical Science Basis, Contribution of Working Group I to the Fifth Assessment Report of the Intergovernmental Panel on Climate Change. Cambridge University Press, Cambridge, UK.

Pubmed: Author and Title

Google Scholar: Author Only Title Only Author and Title

Khaleghi A, Naderi R, Brunetti C, Maserti BE, Salami SA, Babalar M (2019) Morphological, physiochemical and antioxidant responses of Maclura pomifera to drought stress. Sci Rep 9: 19250

Pubmed: Author and Title

Google Scholar: Author Only Title Only Author and Title

Lajeunesse MJ (2016) Facilitating systematic reviews, data extraction and meta-analysis with the metagear package for $r$. Methods in Ecology and Evolution 7: 323-330

Pubmed: Author and Title

Google Scholar: Author Only Title Only Author and Title

Lee DK, Jung H, Jang G, Jeong JS, Kim YS, Ha SH, Do Choi Y, Kim JK (2016) Overexpression of the OsERF71 Transcription Factor Alters Rice Root Structure and Drought Resistance. Plant Physiology 172: 575-588

Pubmed: Author and Title

Google Scholar: Author Only Title Only Author and Title

Lum MS, Hanafi MM, Rafii YM, Akmar ASN (2014) Effect of Drought Stress on Growth, Proline and Antioxidant Enzyme Activities of Upland Rice. Journal of Animal and Plant Sciences 24: 1487-1493

Pubmed: Author and Title

Google Scholar: Author Only Title Only Author and Title

McDowell NG, Beerling DJ, Breshears DD, Fisher RA, Raffa KF, Stitt M (2011) The interdependence of mechanisms underlying climatedriven vegetation mortality. Trends in Ecology \& Evolution 26: 523-532

Pubmed: Author and Title

Google Scholar: Author Only Title Only Author and Title

Mirzaee M, Moieni A, Ghanati F (2013) Effects of Drought Stress on the Lipid Peroxidation and Antioxidant Enzyme Activities in Two Canola (Brassica napus L.) Cultivars. Journal of Agricultural Science and Technology 15: 593-602

Pubmed: Author and Title

Google Scholar: Author Only Title Only Author and Title

Mitchell PJ, O'Grady AP, Tissue DT, White DA, Ottenschlaeger ML, Pinkard EA(2013) Drought response strategies define the relative contributions of hydraulic dysfunction and carbohydrate depletion during tree mortality. New Phytologist 197: $862-872$

Pubmed: Author and Title

Google Scholar: Author Only Title Only Author and Title

Mittler R (2002) Oxidative Stress, Antioxidants and Stress Tolerance. Trends in plant science 7: 405-410

Pubmed: Author and Title

Google Scholar: Author Only Title Only Author and Title 
Murray MB, Cape JN, Fowler D (1989) Quantification of Frost Damage in Plant Tissues by Rates of Electrolyte Leakage. The New Phytologist 113: 307-311

Pubmed: Author and Title

Google Scholar: Author Only Title Only Author and Title

Nikoleta-Kleio D, Theodoros D, Roussos PA(2020) Antioxidant defense system in young olive plants against drought stress and mitigation of adverse effects through external application of alleviating products. Scientia Horticulturae 259: 11

Pubmed: Author and Title

Google Scholar: Author Only Title Only Author and Title

Per TS, Khan NA, Reddy PS, Masood A, Hasanuzzaman M, Khan MIR, Anjum NA(2017) Approaches in modulating proline metabolism in plants for salt and drought stress tolerance: Phytohormones, mineral nutrients and transgenics. Plant Physiology and Biochemistry 115: 126-140

Pubmed: Author and Title

Google Scholar: Author Only Title Only Author and Title

R Development Core Team (2019) R: A language and environment for statistical computing. In, Ed 3.6.0. R Foundation for Statistical Computing, Vienna, Austria, http://umw.Rproject.org/

Pubmed: Author and Title

Google Scholar: Author Only Title Only Author and Title

Rigui AP, Carvalho V, Wendt Dos Santos AL, Morvan-Bertrand A, Prud'homme MP, Machado de Carvalho MA, Gaspar M (2019) Fructan and antioxidant metabolisms in plants of Lolium perenne under drought are modulated by exogenous nitric oxide. Plant Physiol

Biochem 145: 205-215

Pubmed: Author and Title

Google Scholar: Author Only Title Only Author and Title

Saglam A, Saruhan N, Terzi R, Kadioglu A(2011) The relations between antioxidant enzymes and chlorophyll fluorescence parameters in common bean cultivars differing in sensitivity to drought stress. Russian Journal of Plant Physiology 58: 60-68

Pubmed: Author and Title

Google Scholar: Author Only Title Only Author and Title

Schneider JR, Caverzan A Chavarria G (2018) Water deficit stress, ROS involvement, and plant performance. Archives of Agronomy and Soil Science 65: 1160-1181

Pubmed: Author and Title

Google Scholar: Author Only Title Only Author and Title

Sedaghat M, Tahmasebi-Sarvestani Z, Emam Y, Mokhtassi-Bidgoli A(2017) Physiological and antioxidant responses of winter wheat cultivars to strigolactone and salicylic acid in drought. Plant Physiology and Biochemistry 119: 59-69

Pubmed: Author and Title

Google Scholar: Author Only Title Only Author and Title

Sperdouli I, Moustakas M (2012) Interaction of proline, sugars, and anthocyanins during photosynthetic acclimation of Arabidopsis thaliana to drought stress. Journal of Plant Physiology 169: 577-585

Pubmed: Author and Title

Google Scholar: Author Only Title Only Author and Title

Sun Y, Sun P, Wang C, Liao J, Ni J, Zhang T, Wang R, Ruan H (2019) Growth, physiological function, and antioxidant defense system responses of Lemna minor L. to decabromodiphenyl ether (BDE-209) induced phytotoxicity. Plant Physiol Biochem 139: 113-120

Pubmed: Author and Title

Google Scholar: Author Only Title Only Author and Title

Sun Y, Wang C, Xu X, Ruan H (2019) Responses of plants to polybrominated diphenyl ethers (PBDEs) induced phytotoxicity: A hierarchical meta-analysis. Chemosphere 240: 124865

Pubmed: Author and Title

Google Scholar: Author Only Title Only Author and Title

Tang YP, Sun X, Wen T, Liu MJ, Yang MY, Chen XF (2017) Implications of terminal oxidase function in regulation of salicylic acid on soybean seedling photosynthetic performance under water stress. Plant Physiology and Biochemistry 112: 19-28

Pubmed: Author and Title

Google Scholar: Author Only Title Only Author and Title

van der Molen MK, Dolman AJ, Ciais P, Eglin T, Gobron N, Law BE, Meir P, Peters W, Phillips OL, Reichstein M, Chen T, Dekker SC, Doubkova M, Friedl MA, Jung M, van den Hurk BJJM, de Jeu RAM, Kruijt B, Ohta T, Rebel KT, Plummer S, Seneviratne SI, Sitch S, Teuling AJ, van der Werf GR, Wang G (2011) Drought and ecosystem carbon cycling. Agricultural and Forest Meteorology 151: 765-773 Pubmed: Author and Title

Google Scholar: Author Only Title Only Author and Title

Viechtbauer W(2010) Conducting Meta-Analyses in R with the metafor Package. Journal of Statistical Software 36: 1-48

Pubmed: Author and Title

Google Scholar: Author Only Title Only Author and Title

Wallace JG, Zhang XC, Beyene Y, Semagn K, Olsen M, Prasanna BM, Buckler ES (2016) Genome-wide Association for Plant Height and Flowering Time across 15 Tropical Maize Populations under Managed Drought Stress and Well-Watered Conditions in Sub-Saharan 
Africa. Crop Science 56: 2365-2378

Pubmed: Author and Title

Google Scholar: Author Only Title Only Author and Title

Zhang C, Li X, He YF, Zhang JF, Yan T, Liu XL (2017) Physiological investigation of C-4-phosphoenolpyruvate-carboxylase-introduced rice line shows that sucrose metabolism is involved in the improved drought tolerance. Plant Physiology and Biochemistry 115: 328342

Pubmed: Author and Title

Google Scholar: Author Only Title Only Author and Title

Zwicke M, Picon-Cochard C, Morvan-Bertrand A, Prud'homme MP, Volaire F (2015) What functional strategies drive drought survival and recovery of perennial species from upland grassland? Annals of Botany 116: 1001-1015

Pubmed: Author and Title

Google Scholar: Author Only Title Only Author and Title 